\title{
Surgical removal of an intramedullary haematoma simulating Wallenberg's syndrome
}

\author{
LUDWIG G. KEMPE
}

From the Walter Reed General Hospital, Washington, D.C., U.S.A.

This is the report of a young man who presented with the signs and symptoms of the Wallenberg syndrome. After pneumoencephalographic studies a defect was seen in the fourth ventricle and at operation an intramedullary haematoma was discovered and evacuated.

\section{CASE REPORT}

A 25-year-old white male was in an automobile accident receiving a laceration of the left temporal scalp without associated loss of consciousness. Four months later the patient observed decreased hearing on the left with tinnitus. One week thereafter a rise of temperature, nausea, vomiting, hiccoughs, vertigo, and diarrhoea were recorded. In the succeeding 24 hours he became lethargic and was admitted to hospital. Examination demonstrated slight lethargy but excellent general orientation; he walked with a wide base tending to fall to the left. Headaches were not bothersome and the neck was supple. Bilateral horizontal nystagmus was present, more pronounced on looking to the left. Hypoaesthesia and hypoalgesia could be demonstrated over the left side of the face as well as a peripheral left facial weakness. He could not hear from the left ear and caloric stimulation produced no response. The gag reflex on the left could not be obtained. Sensory examination of the remaining parts of the body was quite normal and spontaneous discomfort was never mentioned. The deep tendon reflexes were abnormally brisk on the left with a left extensor toe response. All the musculature of the left arm and leg was weak, with increased tonus. Sweating was absent on the left side of the body with the exception of the face.

LABORATORY STUDIES Haematological studies were normal. The Kahn test was negative. Skull radiographs and an electroencephalogram were not abnormal. The visual fields were unaffected and the cerebrospinal fluid was under normal pressure without chemical or cytological abnormality.

COURSE IN THE HOSPITAL It initially appeared that the patient had suffered a lateral medullary infarction. The fever, diarrhoea, and hiccoughs abated within six days and within 20 days hearing returned to normal. The response to caloric stimulation also returned but there was little change in the other neurological signs an symptoms. Six weeks from admission the patient stilis. experienced episodes of lethargy, nausea, and vomiting Because of the persistence of the latter symptoms a pneumoencephalogram was recommended, although it was still felt that a lateral medullary infarction was the most probable diagnosis.

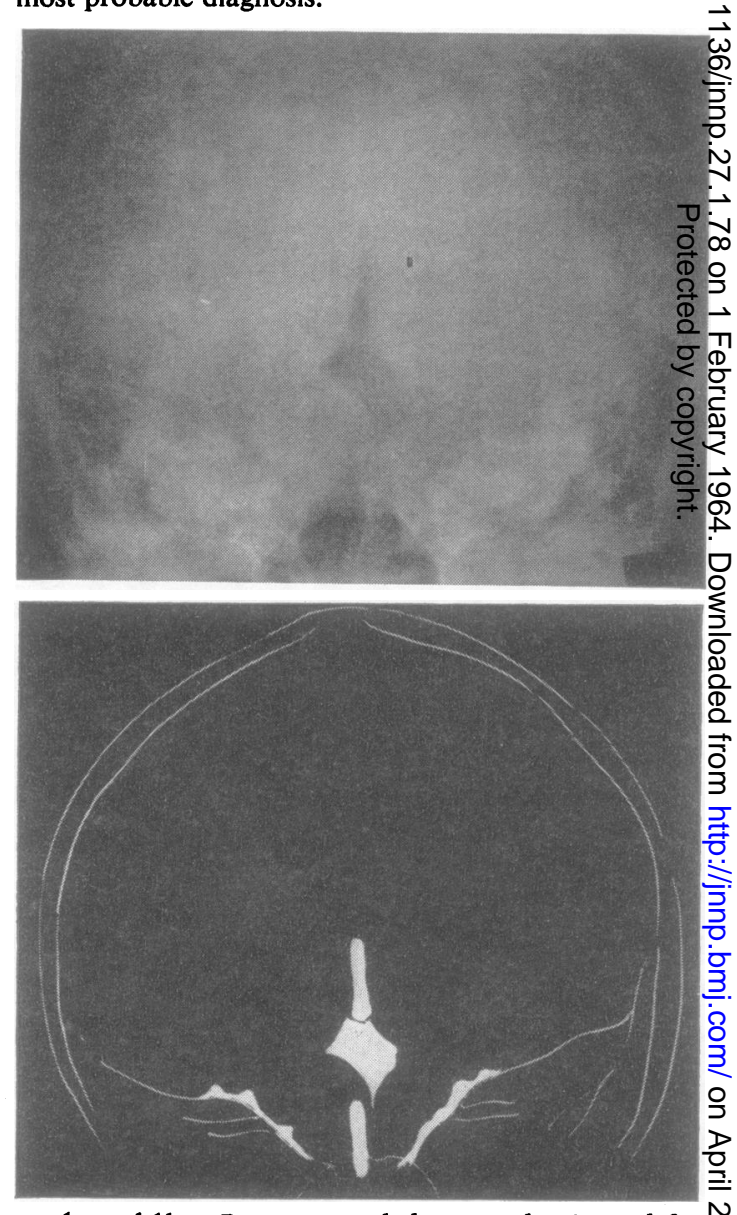

FIGs 1a and 1b. Pneumoencephalograms showing a defecter in the rhomboid fossa but no displacement of the fourth ventricle or vallecula. 


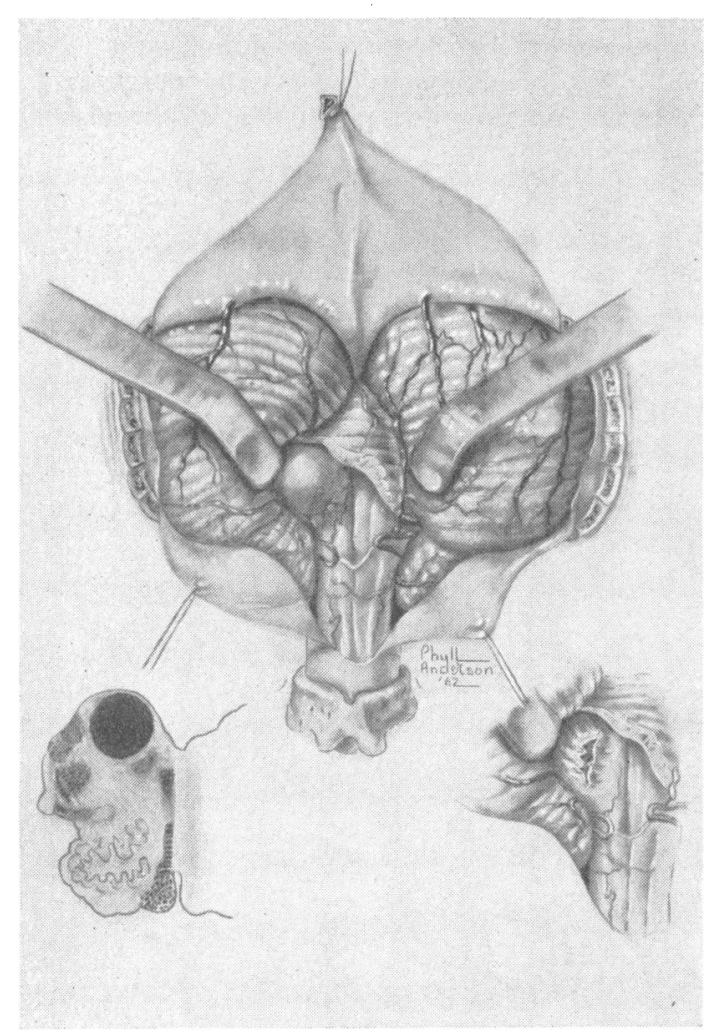

FIG. 2. Drawing of the membrane-like dome found and incised at operation.

The pneumoencephalogram (Figs. 1a and $1 \mathrm{~b}$ ) revealed a defect in the rhomboid fossa without displacement of the fourth ventricle or vallecula. The pontocerebellar angles were of normal configuration.

OPERATIVE FINDINGS A suboccipital craniectomy revealed a $1.5 \mathrm{~cm}$., round elevation of the floor of the fourth ventricle on the left, medial to the restiform body (Fig. 2). There was a brownish discoloration over the dome of the elevation suggesting an underlying haematoma. The membrane-like dome was incised and a perfectly round, clotted, haematoma-like mass was evacuated. Inspection of the remaining cavity did not show any abnormal vascular pattern or semblance of tumour. Microscopic examination of the specimen revealed no vascular structures or neoplasm. Three weeks after the operation a neurological examination displayed dysmetria of the left upper extremity in finger-to-nose and finger-to-finger testing. Six months after surgery only the dysmetria of the upper extremity remained.

\section{DISCUSSION}

The pre-operative clinical impression that the patient was suffering from a lateral medullary infarction appeared justified. A history of antecedent trauma several months before admission to hospital has been reported by Currier, Giles, and DeJong (1961) in three out of 39 patients with medullary infarction. Loss of hearing seems to be a unique feature. Nausea and vomiting are frequently an early component of lateral medullary infarction, resolving as the full clinical picture develops. The persistence of these signs coupled with recurrent episodes of lethargy aroused suspicion and led to pneumoencephalography. Vertebral angiographic studies have been disappointing in the investigation of most similar problems, and may subject the patient to needless danger. The study of Fisher, Karnes, and Kubik (1961) has demonstrated that the larger branches of the vertebral basilar circulation are not necessarily involved in medullary infarction. The very fine paramedial circumferential branches are most often responsible. These are difficult to visualize through the overlying petrosal bone. From personal experience we agree with Yasargil (1962) who doubts that a small arteriovenous malformation can be demonstrated by vertebral angiography. A small vascular malformation was not included in the differential diagnosis as the patient had clear cerebrospinal fluid on two occasions.

As a result of our reluctance to perform angiography of the vertebral basilar system when arteriosclerotic disease was considered, a pneumoencephalogram was selected as the safest procedure as well as the one most likely to demonstrate another cause for the clinical picture of medullary infarction. Although microscopic examination of the surgical specimen did not reveal any vascular structure we believe that the aetiology of this haematoma was a small vascular malformation. The age of the patient and 'the spontaneous onset and even occasional history of slight trauma', as mentioned by Margolis, Odom, and Woodhall (1961), support our contention. The absence of any vascular structures in the operative specimen does not obviate the possibility of a small angiomatous malformation of the 'cryptic arteriovenous and venous hamartoma' type noted by Crawford and Russell (1956). These authors emphasized the smallness of the lesions, relative young ages of the patients, and the history of trauma in several cases. Wilson, Ornsteen, and Sagen (1951) described a posterior-inferior cerebellar artery syndrome in a 20 -year-old man. No definite diagnosis was made in this patient but the authors gave the following aetiological possibilities for the lateral medullary syndrome in young persons: Syphilis, subacute bacterial endocarditis, embolism, aneurysm of the posterior-inferior cerebellar artery, tumour of the area of supply of this artery, as well as metastases, Hodgkin's disease, tuberculoma, and 
multiple sclerosis. The author states: 'I discovered no cases in the literature of haemorrhage alone as a primary cause of this syndrome. It does, of course, occur secondary to thrombosis or tumour in the area affected.' We have been unable to find a single case in the literature with clinical and surgical correlation. The hypothesis that the lesion was the result of a small vascular malformation destroying itself at the time of rupture seems most acceptable.

SUMMARY

One case of the Wallenberg syndrome is reported. The pneumoencephalographic study showed a mass lesion of the fourth ventricle and at operation a昂 intramedullary haematoma was found and evacu? ated. The possibility of a small arteriovenous malformation being the aetiology is discussed.

\section{REFERENCES}

Crawford, J. V., and Russell, D. S. (1956). J. Neurol. Neurosurfo Psychiat., 19, 1.

Currier, R. D., Giles, C. L., and DeJong, R. N. (1961). Neurof (Minneap)., 11, 778.

Fisher, C. M., Karnes, W. E., and Kubik, C. S. (1961). J. Neuropat还 exp. Neurol., 20, 323.

Margolis, G., Odom, G. L., and Woodhall, B. (1961). J. Neuropat exp. Neurol., 20, 161.

Wilson, G., Ornsteen, A. M., and Sagen, W. (1951). Arch. Neurof Psychiat., 66, 530.

Yasargil, G. (1962). Acta Neurochirurg., Suppl. 9, 82.

\section{The December 1963 Issue}

\section{THE DECEMBER 1963 ISSUE CONTAINS THE FOLLOWING PAPERS}

The relationship between enzyme activity and neuroglia in the prodromal and demyelinating stages of cyanide encephalopathy in the rat M. Z. M. IBRAHIM, PHILANDER B. BRISCOE, JR., OLGA B. BAYLISS, and C. W. M. ADAMS

The descending respiratory pathway in man P. W. NATHAN

Effect of alpha methyl dopa on experimental tremor H. SCHNIEDEN

A controlled clinical trial of alpha methyl dopa in Parkinsonian tremor D. O. MARSH, H. SCHNIEDEN, and JOHN MARSHALL

Hereditary spastic ataxia simulating disseminated sclerosis MOHSEN MAHLOUDJI

Veterinary workers and disseminated sclerosis A. M. G. CAMPBELL
Hereditary spastic paraplegia PETER F. ROE

Nerve fibre size in the carpal tunnel syndrome P. K. THOMAS and P. M. FULLERTON

Aberrant nerve fibres within the spinal cord TREVOR HUGHES and BETTY BROWNELL

Cerebral pathology in subarachnoid haemorrhage BARBARA SMITH

A perceptual maze test sensitive to brain damage A. L. BENTON, A. ELITHORN, M. L. FOGEL, and M. KER

Studies in spina bifida Part IV The frequency and extent of paralysis P. A. DORAN and A. N. GUTHKELCA

Proceedings of the Society of British Neurologica?

Surgeons: 68th meeting

Book reviews

Index to volume XXVI

Copies are still available and may be obtained from the PUBLISHING MANAGER, BRITISH MEDICAL ASSOCIATION, TAVISTOCK SQUARE, W.C.I., price 18s. 6D. 